\title{
Documenting the Constraints and Its Allied Factors in Agar (Aquilaria malaccensis Roxb.) Tree Cultivation at Farm Level: A Case Study in Bangladesh
}

\author{
Md. Iqbal Hossain, Md. Abiar Rahman, Satya Ranjan Saha, Md. Mizanur Rahman, \\ Md. Safiul Islam Afrad, and Jannatul Ferdousi
}

\section{ABSTRACT}

The study was conducted to investigate the socio-economic characteristics of the agar farmers, the extent of constraints in agar wood cultivation; and the factors allied with constraints in agar tree farming. Despite the enormous potential of agar (Aquilaria malaccensis Roxb.) production in Bangladesh, it has yet to gain traction due to socioeconomic, technical, and marketing challenges. The cultivation of agar trees is largely centered in the Sylhet region, where a large number of agar farmers engage. This research was carried out in Maulvibazar district's Barlekha upazila (subdistrict) to better understand and assess the restrictions and factors that affect agar tree cultivation. A survey was conducted with 120 households during September 2018 to March 2019. Descriptive statistics, rank order, coefficient of correlation, and multiple linear regression were used to examine the data. Out of 12 constraints, the most significant barrier was a lack of funds to engage in agar farming (2.81), which was followed by a lack of technical guidance (2.71). The lack of labor was the least important constraint faced by the farmers (1.43). It was revealed that education, household size, farm size, number of trees per farmer, annual income, experience in agar farming, agar wood cultivation under trees and knowledge of agar cultivation of the farmers were shown to be realized to agar plantation constraints. However, education, farm size, annual revenue, and agar growing experience were identified as major drivers of the degree of agar farming constraints. The study identified various policymakers' potential to address the influencing variables (education, farm size, annual revenue, and agar farming experience) in establishing agar farming. Furthermore, finance facilities, adequate agar farming instruction, and forest department introspection could all help to reduce agar farming obstacles.

Keywords: Agar tree cultivation, socio-economic characteristics, constraint, Agar farmers Bangladesh.
Submitted : August 11, 2021

Published : September 02, 202

ISSN: $2684-1827$

DOI: 10.24018 /ejfood.2021.3.5.353

Md. Iqbal Hossain*

PhD Fellow, Dept. of Agroforestry and Environment, Bangabandhu Sheikh Mujibur Rahman Agricultural University, Gazipur-1706, Bangladesh.

(e-mail: iqbalsaubd@ gmail.com)

Md. Abiar Rahman

Professor, Dept. of Agroforestry and Environment, Bangabandhu Sheikh Mujibur Rahman Agricultural University, Gazipur-1706, Bangladesh.

(e-mail: abiar@bsmrau.edu.bd)

Satya Ranjan Saha

Professor, Dept. of Agroforestry and Environment, Bangabandhu Sheikh Mujibur Rahman Agricultural University, Gazipur-1706, Bangladesh.

(e-mail: satya@bsmrau.edu.bd)

Md. Mizanur Rahman

Professor, Dept. Horticulture, Bangabandhu Sheikh Mujibur Rahman Agricultural University, Gazipur-1706, Bangladesh.

(e-mail: mizanur@bsmrau.edu.bd)

Md. Safiul Islam Afrad

Professor, Dept. of Agricultural Extension and Rural Development, Bangabandhu Sheikh Mujibur Rahman Agricultural University, Gazipur-1706, Bangladesh.

(e-mail: afrad69@gmail.com)

Jannatul Ferdousi

Assistant Professor, Dept. Horticulture,

Sylhet Agricultural University, Sylhet,

Bangladesh.

(e-mail: ferdousi.hort ${ }^{@}$ sau.ac.bd)

*Corresponding Author

\section{INTRODUCTION}

Agar wood is a dark resinous heartwood found in the Thymelaeaceae family's Aquilaria and Gyrinops plants [1]. The heartwood is light and pale in color, but as the wood matures (a term used in a broad sense), the tree develops a dark fragrant resin in response to infection or unknown stimuli, resulting in a dense, dark, resin-encrusted heartwood [2]. According to a study [3,] the trees can reach a height of 6-20 meters. The leaves are alternating in shape, measuring 5-11 cm long and 2-4 cm wide with a short acuminate apex and an entire border. The flowers are yellowish-green in color and produced in an umbel type of inflorescence. The fruit is a $2.5-3 \mathrm{~cm}$ long woody capsule type. They grow in monsoon regions with annual rainfall of around $2000 \mathrm{~mm}$, as well as tropical hills and mountains [4].

Bangladesh, Bhutan, India, Indonesia, Iran, Malaysia, Myanmar, the Philippines, Singapore, and Thailand [5] are among the countries which mostly grow agar trees. They are often found in India's north-eastern mountainous regions [6]. 
Agar trees can be found in the Sylhet, Chittagong, and Chittagong Hill Tracts (CHT) forests of Bangladesh. Agar trees (Aquilaria malaccensis) are currently being widely produced as a plantation species in Bangladesh to supply raw materials for agar-based industries [7]. The crops are one of Bangladesh's most prospective non-timber forest products (NTFPs), which earns huge foreign currency through exporting of attar (agar oil) and other value-added products [8]-[11]. The rising demand for agar oil, particularly in global markets, has boosted agar businesses even in Bangladesh's rural areas. The Moulvibazar district in Bangladesh's north-eastern region is one of the welldocumented places for agar crops and agar oil production [12]. A total of 111 of the country's 121 registered agar enterprises are located in the region, making significant contributions to regional employment and GDP [9], [12].

Agar tree (Aquilaria malaccensis Roxb.) is one of the high value industrial tree species. Its wood is the most expensive one in the world and extensively used in manufacturing of luxury perfume, soap, and different cosmetics [2]. In 2014, Bangladesh government officially declared agar production as an industrial sector [4]. About 25000-30000 workers are engaged in cultivation to marketing of agar and agar-based products in the country [13], [11]. Currently, Bangladesh earns about 50 crore Tk. $\mathrm{yr}^{-1}$ by exporting agar through informal sector, but it can be raised to over 100 crore Tk. by improving and developing this sector [14]. The plantation area of this valuable crop is rapidly declining in natural forests due to over exploitation in the country. Unfortunately, the agar wood production is mostly confined in Moulavibazar district [15].

Farmers usually grow agar tree without being following the modern production techniques. Though there are enough scope to expand the production of agar tree in different agro-ecosystems of Bangladesh, yet it is underrated due to proper field study [9], [10].

Some studies [16], [17] opined through this studies that the Moulvibazar district, the cultivation of agar trees under a public-private partnership and agar oil manufacturing firms have changed the lives of many underprivileged people by providing socioeconomic benefits.

Despite some obstacles to agar farming, such as traditional agar tree wounding techniques and the use of intermediaries in the marketing of agar trees and agar-based products, this economic sector has the potential to play a critical role in rural people's livelihood subsistence and Bangladesh's forestry sector development [12]. It's a good idea to plant agar trees along field boundaries and divide a plot into sub-plots. Gardens, school grounds, office grounds, parks, and residential areas all have agar trees growing on the boundaries. Its ability to pollard and coppice well has made it a promising agroforestry candidate [18].

Although agar is in high demand in both national and international markets, governments or NGOs in Bangladesh have not yet implemented any major expansion programs [19]. Though there is a huge prospect of Agar production in Bangladesh, there are some problems during cultivation and marketing; which are essential to be addressed to increase the production. We must ensure the quality and market of the agar we produce because it is a high-value non-timber forest product [19].The aim of the study was to explore the constrains facing in agar tree production.

The study's specific goals were to investigate into the socioeconomic characteristics of agar farmers, the level of constraints in agar wood cultivation, and factors attributed to agar tree farming constraints. The relation between respondent's socio-economic factors (explanatory variables) and their restrictions in agar cultivation was evaluated using a null hypothesis (H0) (focus variable). Where $\mathrm{H} 0$ indicates that the explanatory and focus variables have no relationship.

\section{METHODOLOGY}

\section{A. Study Area}

The research was carried out in Bangladesh's Maulvibazar district's Barlekha upazila (sub-district). The upazila of Barlekha is located between the latitudes of $24^{\circ} 33^{\prime \prime}$ and $24^{\circ} 50^{\prime \prime}$ north and the longitudes of $92^{\circ} 02^{\prime \prime}$ and $92^{\circ} 18^{\prime \prime}$ east (Fig. 1). In Bangladesh's Moulvibazar district, there are about 300 agar-based enterprises [4], [12]. The Barlekha upazila, one of the seven upazilas of Moulvibazar district, is present in the majority of agar crops and agar oil businesses. As a result, the study area was chosen with respect in Barlekha upazila. Beanibazar upazila in the north, Kulaura upazila in the south, Golabganj and Fenchuganj upazila in the west, and India in the east surround the research region. Grey Piedmont soils and Non-calcareous Grey Floodplain soils are the two main soil types in the area [20], [12]. The texture of these soils ranges from loam to clay, with a slightly acidic to highly acidic reaction. [20], [12], the fertility level is low to medium.
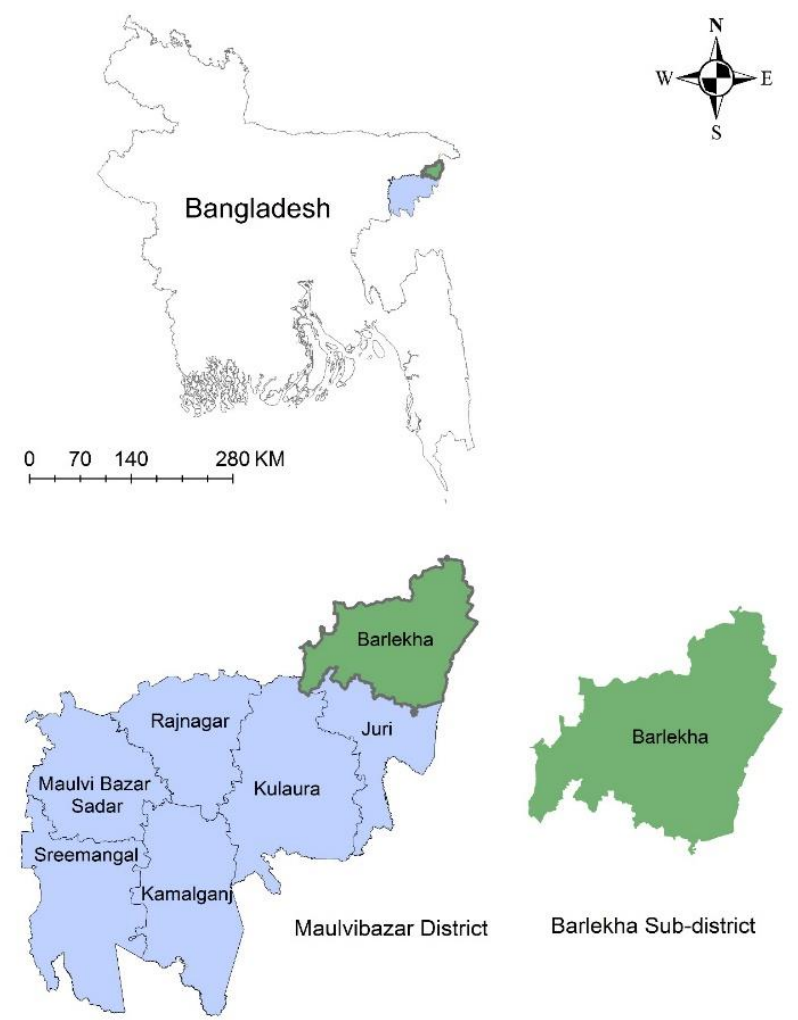

Barlekha Sub-district

Fig. 1. The study area is shown on a map of Bangladesh and the Maulvibazar district. 


\section{B. Data Collection and Analysis Methods}

A survey was conducted in six villages under two unions viz. Sujanagar and Dakshinbhag in the Barlekha upazila of Moulvibazar district, Bangladesh. Based on the quantity of agar trees, villages were classified as A, B, or C. The poll included two communities from each category. Each of the six villages had a total of 20 agar farmers selected at random.

From September 2018 to March 2019, the study used a face-to-face interview method. The questions were designed to obtain information on the respondents' socioeconomic status, understanding of agar wood production, and agar tree farming limitations. The study's main goals were to define the socioeconomic features of agar farmers, determine the level of restraints, and identify factors associated with agar tree farming constraints.

The number of restrictions in agar wood cultivation in the study area was determined using a four-point rating scale. The FGDs and relevant literature revealed a total of twelve (12) restrictions in agar wood cultivation. High constraint, medium constraint, low constraint, and none at all were the four options for each constraint, with scores of 3,2, 1, and 0 corresponding to each. As a result, the scale score ranged from 0 to 36 , with 36 indicating the most severe limitation and 0 indicating no constraint. The severity of limitations was categorized into three groups based on the score: low, moderate, and severe.

The following descriptive statistics were used to determine the socio-economic characteristics of the agar tree farmers in the study: mean, standard error (SE), standard deviation (SD), and percentage. Descriptive statistics are used to explain the qualities and basic characteristics of study participants [21].

To determine the number of restrictions in agar tree cultivation, a constraint facing index was developed (CFI). The CFI aids in the identification of the most pressing issues confronting agar tree producers in the research region (Eq. (1)) [22]- [24].

$$
\mathbf{C F I}=\left(\mathrm{C}_{\mathrm{h}} \times 3+\mathrm{C}_{\mathrm{m}} \times 2+\mathrm{C}_{\mathrm{l}} \times 1+\mathrm{C}_{\mathrm{n}} \times 0\right) / \mathrm{N}
$$

where CFI is the number of responses with high constraints, $\mathrm{Cm}$ denotes the number of responses with a medium problem, $\mathrm{Cl}$ denotes the number of responses with a low problem, $\mathrm{Cn}$ denotes the number of responses with no difficulty, and $\mathrm{N}$ denotes the total number of responses.

Correlation and regression analysis were used to determine the parameters associated with constraints in agar tree farming. The data were cleaned, coded, and analyzed using the statistical program for social science (SPSS) version 20 for the analysis. For the creation of various charts and graphs, Microsoft Excel 13 was used. Pearson's productmoment correlation coefficient (2) was used to investigate the relationship between the independent and focal variables.

$$
\mathbf{r}_{\mathbf{x y}}=\frac{\sum\left(\mathrm{x}_{1}-\bar{x}\right)\left(\mathrm{y}_{1}-\overline{\mathrm{y}}\right)}{\sqrt{\sum\left(\mathrm{x}_{1}-\bar{x}\right)^{2} \sum\left(\mathrm{y}_{1}-\overline{\mathrm{y}}\right)^{2}}}
$$

where

$\mathrm{r}_{\mathrm{xy}}=$ Pearson's product-moment correlation coefficient; $\bar{x}$ and $\bar{y}=$ Means of the variables $\mathrm{x}$ and $\mathrm{y}$, respectively

The factors related to agar farmers' restrictions in agar production were determined using multiple regression analysis (entry technique) [25]. The multiple regression analysis equation is as follows (3):

$$
\begin{aligned}
\mathbf{y}_{1}=\beta_{0}+\beta_{1} X_{1}+\beta_{2} X_{2}+\beta_{3} X_{3}+\beta_{4} X_{4}+\beta_{5} X_{5}+\beta_{6} X_{6}+\beta_{7} X_{7+} \\
\beta_{8} X_{8}+\beta_{9} X_{9}+\beta_{10} X_{10+\epsilon)}
\end{aligned}
$$

where,

$\mathrm{y}_{1=} \quad$ Constraints in agar tree cultivation,

$\beta_{0}=$ Constant;

$\mathrm{X}_{1}=$ In years, the respondents' age;

$\mathrm{X}_{2}=$ Education qualification of the respondents in years;

$\mathrm{X}_{3}=$ Household size of the respondents,

$\mathrm{X}_{4}=$ Homestead size,

$\mathrm{X}_{5}=$ Farm size,

$\mathrm{X}_{6}=$ Total number of agar tree per farmer,

$\mathrm{X}_{7}=$ Annual family income,

$\mathrm{X}_{8}=$ Experience in agar cultivation,

$\mathrm{X}_{9}=$ Agar wood cultivation under trees,

$\mathrm{X}_{10}=$ Knowledge of Agar cultivation,

$\varepsilon_{1}=$ Term for an error.

\section{RESUlts AND DisCUSSION}

\section{A. Socio-economic Characteristics of Agar Farmers}

The socio-economic characteristics of the respondents has been displayed in Table I. Among 120 agar farmers, 49.20 $\%$ respondents were middle-aged followed by old aged $(29.20 \%)$. The sample farmers of the study area were categorized into five groups on the basis of their education viz. illiterate, primary (class 1 to 5), secondary (class 6 to 10), higher secondary (class 11 to 12 ) and Graduate (above class 12 which indicates hons./degree/graduation/postgraduation). Observed range of educational status of the respondents were $0-16$ with an average of 7.64. Majority of the respondents $(40.80 \%)$ had primary education. The findings indicated that most of the farmers' education status was up to primary and secondary level in Barlekha upazila. This result was in conformity with the information cited in [26]. Education has an impact on farmers' perspectives, attitudes, and tendencies toward modernisation of traditional agriculture [27], and it can also help farmers understand technical details and overcome obstacles [28]. Through a study [29] indicated that the farmer's educational level has an impact on management and the adoption of appropriate technologies. The respondents had an average of 6.29 family members, with 51.70 percent belonging to a medium household. Living with parents, brothers, sisters, and occasionally relatives is fairly prevalent in the Sylhet division [10]. The respondents were categorized into five different groups as shown in table 1 according to the size of the homestead. Marginal $(36.70 \%)$ and landless group $(34.2 \%)$ were found maximum compared to small $(20.80 \%)$, medium $(5.20 \%)$ and large group $(3.30 \%)$.

Majority of the respondents $(91.70 \%)$ had small farm holdings and 5.8\% had the medium farm holdings (1.01-3.0 ha) under agar wood cultivation. Only $2.5 \%$ had the large farm holders (>3.0 ha). The number of agar trees per farmer 
varied significantly and it was found that $53.3 \%$ respondents belonged to small group followed by medium $(41.70 \%)$ and large $(5.0 \%)$ with the SD of 3770.74 . Based on the annual family income, the respondents were observed to be maximum under the small group $(48.30 \%)$ followed by medium group $(35.80 \%)$. Only $5.0 \%$ belonged to the large group having monthly annual income of BDT > 300 thousand. Annual income of the respondents ranged from Tk. 65 to 1800 thousand with an average value of Tk. 220.80 thousand. The findings implied that the farmers in the research area had a low level of income. About $15.0 \%$ of farmers had no experience, $55 \%$ had 11-21 years of experience, and $30 \%$ had more than 22 years of expertise with agar cultivation (Table I).

\begin{tabular}{|c|c|c|c|}
\hline Category & $\begin{array}{l}\text { Respondents } \\
\text { (percent) }\end{array}$ & $\begin{array}{c}\text { Mean } \pm \\
\text { SE }\end{array}$ & $\mathrm{SD}^{*}$ \\
\hline \multicolumn{4}{|l|}{ Age (years) } \\
\hline Young $(<35)$ & 21.70 & \multirow{3}{*}{$\begin{array}{c}46.79 \\
( \pm 1.17)\end{array}$} & \multirow{3}{*}{12.80} \\
\hline Middle (35-50) & 49.20 & & \\
\hline Old $(>50)$ & 29.20 & & \\
\hline \multicolumn{4}{|c|}{ Education (years of schooling) } \\
\hline Illiterate (No schooling) & 10.00 & \multirow{5}{*}{$\begin{array}{c}7.64 \\
( \pm 0.37)\end{array}$} & \multirow{5}{*}{4.10} \\
\hline Primary $(1-5)$ & 40.80 & & \\
\hline Secondary (6-10) & 23.30 & & \\
\hline Higher secondary (11-12) & 17.50 & & \\
\hline Graduate (above 12) & 8.30 & & \\
\hline \multicolumn{4}{|l|}{ Household size (number) } \\
\hline Small $(\leq 4)$ & 35.80 & \multirow{3}{*}{$\begin{array}{c}6.29 \\
( \pm 0.18)\end{array}$} & \multirow{3}{*}{1.99} \\
\hline Medium (5-8) & 51.70 & & \\
\hline Large $(>8)$ & 12.50 & & \\
\hline \multicolumn{4}{|l|}{ Homestead size (ha) } \\
\hline Landless (up to 0.05 ) & 34.2 & \multirow{5}{*}{$\begin{array}{c}0.095 \\
( \pm 0.006)\end{array}$} & \multirow{5}{*}{0.074} \\
\hline Marginal (0.05-0.10) & 36.7 & & \\
\hline Small (0.11-0.20) & 20.8 & & \\
\hline Medium (0.21-0.3) & 5.0 & & \\
\hline Large $(>03)$ & 3.3 & & \\
\hline \multicolumn{4}{|l|}{ Farm size (ha) } \\
\hline Small $(0.2-1)$ & 91.70 & \multirow{3}{*}{$\begin{array}{c}0.51 \\
( \pm 0.06)\end{array}$} & \multirow{3}{*}{0.68} \\
\hline Medium (1.01-3) & 5.80 & & \\
\hline Large (above 3 ) & 2.50 & & \\
\hline \multicolumn{4}{|c|}{ Total number of agar tree per farmer } \\
\hline Small (up to 1000) & 53.3 & \multirow{3}{*}{$\begin{array}{c}2195.33 \\
( \pm 344.21)\end{array}$} & \multirow{3}{*}{3770.74} \\
\hline Medium (1001 to 10000$)$ & 41.7 & & \\
\hline Large (above 10000) & 5.0 & & \\
\hline \multicolumn{4}{|c|}{ Annual family income ('000' BDT) } \\
\hline Low (up to 150 ) & 48.3 & \multirow{3}{*}{$\begin{array}{c}220.82 \\
( \pm 19.25)\end{array}$} & \multirow{3}{*}{210.93} \\
\hline Medium (151-300) & 35.8 & & \\
\hline High (above 300) & 15.8 & & \\
\hline \multicolumn{4}{|c|}{ Experience in agar cultivation (years) } \\
\hline Low (up to 10$)$ & 15.00 & \multirow{3}{*}{$\begin{array}{c}21.55 \\
( \pm 1.05)\end{array}$} & \multirow{3}{*}{11.56} \\
\hline Medium (11-21) & 55.00 & & \\
\hline High (above 22) & 30.00 & & \\
\hline \multicolumn{4}{|c|}{ Agar wood cultivation under trees (years) } \\
\hline Low (up to 10$)$ & 10.00 & & \\
\hline Medium (11-20) & 65.00 & 19.96 & 9.00 \\
\hline High (above 20) & 25.00 & & \\
\hline Knowledge of Agar cultivat & (Possible scor & $0-30)$ & \\
\hline Low (up to 10$)$ & 4.2 & & \\
\hline Moderate (11-12) & 51.7 & 20.39 & 6.45 \\
\hline High (21-30) & 44.2 & $( \pm 0.59)$ & \\
\hline
\end{tabular}

SD* = standard deviation; $\mathrm{SE}=$ std. error; BDT stands for Bangladeshi Taka, and 1 BDT is worth $0.012 \$$.

Ten percent respondents had the less experience on agar cultivation under trees which had been categorized as low (up to 10 years) with a mean of $19.96( \pm 0.82)$. It was revealed that the old and middle-aged people with low-level of education and long experience were engaged in agar production activities [30]. Farmers with long experience can predict farm production and market situation [28]. Majority of the respondents (65\%) had medium (11-20 years) experience on agar wood cultivation under trees, followed by high $(25 \%)$. Asking 10 questions to judge the knowledge level of the respondents on agar tree cultivation; it was found that the highest proportion $(51.7 \%)$ of the respondents possessed moderate knowledge on agar wood farming (Table I) followed by high knowledge $(44.20 \%)$. A study [31] indicated in a Bangladeshi that knowledge was a critical component influencing people's attentiveness and mental awareness.

\section{B. Extent of Constraints in Agar Cultivation}

The extent of constraints in agar cultivation faced by the farmers is displayed in Fig. 2. The result showed that majority of the respondents $(64.17 \%)$ had severe constraints followed by moderate constraints $(35.83 \%)$. Whereas no farmer $(0 \%)$ reported low constraints in agar cultivation in the study area. The findings implied that the agar farmers experienced a great difficulty in agar cultivation. Those restrictions could be caused by a variety of circumstances. Low agar tree farmer income, a lack of professional guidance on agar wood cultivation, and limited access to enhance variety could all be factors contributing to severe agar tree cultivation constraints in the research location. The data also revealed that there is a potential to implement interventions aimed at reducing the restrictions. Farmers in Bangladesh face moderate to severe difficulties (87 percent) in managing agar tree farming, according to a study [12], which supports the current findings. Farmers in Maulvibazar District experienced high to moderate limitations (89.19 percent) while embracing agar wood cultivation, according to a study [17], which strongly corroborated the findings of the current analysis.

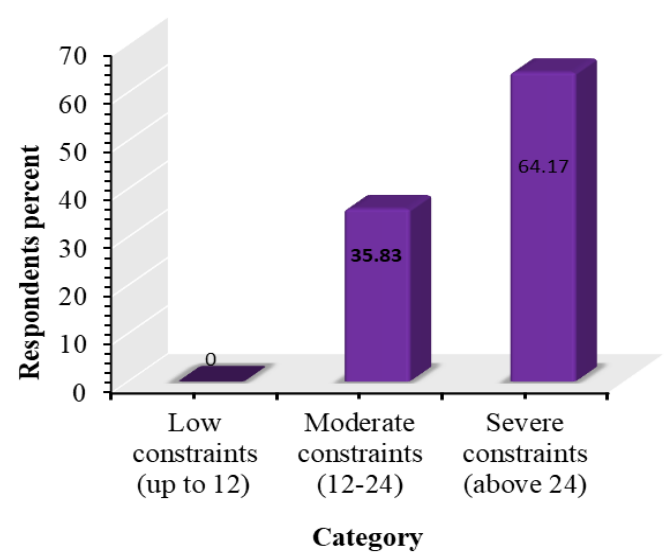

Fig. 2. Degree of pitfalls in agar cultivation in the study area $(\mathrm{n}=120)$

A CFI was calculated and displayed in rank order (Table II). The data revealed that the most significant constraint to agar producers was a lack of funds to invest in agar tree production, with a CFI score of 2.81. According to [10], [17]; agar-wood production cost is very high and all the farmers in the study area were not economically solvent for which they the interviewed farmers in the study area mainly belonged to the low-income group they need money for running their farming operations, but credit was available 
only at a very high interest rate (Table I). Another study [12] also reported that lack of credit facilities was the major problem in agar production and processing. Likewise, a lack of credit support could be another factor limiting investment (Table I). The second most important barrier in agar tree cultivation was a lack of technical guidance $(\mathrm{CFI}=2.77)$. The majority of the farmers in the research area grew agar trees on a semi-intensive basis.

Unavailability of improved variety $(\mathrm{CFI}=2.63)$ was the third critical constraint to the farmers. The growth and quality of agar plant in respect of oil extraction largely depends on improved variety. Low quality variety can easily be affected by different insects and diseases [30]. Lack of improved technology $(\mathrm{CFI}=2.48)$ was the fourth critical constraint to the agar tree farmers. However, lack of workers $(\mathrm{CFI}=1.43)$ was the least critical constraint. Without efficient labour, work is not possible in any sector. Some studies [30], [4] opined that in the rainy season shortage of human labour was exhibited in the study area and cost of labour was very high.

\section{The Relationship between Socioeconomic Factors of Farmers and Constraints in the Cultivation of Agar Trees}

The summary of association between explanatory and focus variables is presented in Table III. Five (5) out of ten (10) explanatory variables were found to have a significant relationship with the target variables. The target variable had a negative but significant relationship with all five explanatory variables: education, total number of trees per farmer, annual family income, homestead size, and farm size. As a result, the higher the degree of all of the aforementioned variables, the lower the number of constraints. [24], [33] found that the farmers' knowledge of problems was strongly influenced by their educational level. Farmers that are better educated are more knowledgeable, more able to comprehend and respond to events, and have more access to information [34], [24] and are therefore more likely to face minor limitations. The findings of [35], [24], [12] are also in agreements with the present findings.

Through a study [22] reported that higher education, farm size, a greater number of tree and more annual family income decreased the level of constraints. Another study [35] found that age, education, income, communication exposure, experience, training experience, and expertise were all negatively linked with climbing perch farming limits in Bangladesh.

TABLE III: RELATIONSHIP BETWEEN SOCIO-ECONOMIC CHARACTERISTICS AND CONSTRAINTS IN AGAR CULTIVATION ( $\mathrm{N}=120)$

\begin{tabular}{cccc}
\hline Socio-economic & Correlation of & \multicolumn{2}{c}{ Table value $(\mathrm{r})$} \\
\cline { 3 - 4 } characteristics & coefficient $(\mathrm{r})$ & 0.05 & 0.01 \\
\hline Age & 0.152 & 0.196 & 0.257 \\
Education & $-0.396^{\mathrm{a}}$ & & \\
Household size & 0.119 & & \\
Homestead size & $-0.556^{\mathrm{a}}$ & & \\
$\quad$ Farm size & $-0.586^{\mathrm{a}}$ & & \\
Total number of agar & $-0.497^{\mathrm{a}}$ & & \\
$\quad$ tree per farmer & $-0.564^{\mathrm{a}}$ & & \\
Annual family income & $\begin{array}{l}\text { Experience in agar } \\
\text { cultivation }\end{array}$ & -0.161 & \\
Agar wood cultivation & -0.023 & \\
$\quad$ under trees & & \\
Knowledge of Agar \\
cultivation
\end{tabular}

Correlation is significant at the 0.01 level of confidence, with degree of freedom $(\mathrm{df})=118$. $(2$-tailed $)$.

\section{Factors Related to Problems of the Respondents in Agar Tree Cultivation}

Multiple linear regression analysis was used to assess the determinants and their importance in predicting the target variable, i.e., restrictions in agar tree cultivation. The results of the multiple linear regression investigation are summarized in Table IV. Four out of ten variables were found to be significant, with an F value of 10.15 and an R2 of 0.435 . This meant that the combined effects of explanatory variables might account for around $43 \%$ of agar tree cultivation restrictions. The coefficient of education $(\mathrm{t}=-2.180 ; \mathrm{p}=0.05)$, farm size $(\mathrm{t}=-2.082 ; \mathrm{p}=0.05)$, annual income $(\mathrm{t}=-3.278 ; \mathrm{p}=0.05)$ and experience in agar tree farming $(\mathrm{t}=-2.209 ; \mathrm{p}=0.05)$ had significant influence in predicting the constraints of agar tree cultivation (Table IV). The findings also demonstrated that farmer education had a negative coefficient, implying that as agar farmers' educational levels increased, they were less likely to experience agar tree production constraints in the research area. Specifically, the constraints experienced by farmers will diminish by 0.355 for every unit increase in education. This may explain whether farmers' increased educational levels positively triggered a growth in their ability to deal with limits. [33], [24] both found similar findings.

TABLE II: CONSTRAINTS IN AgAR TREE CULTIVATION FACED BY THE FARMER (N=120)

\begin{tabular}{|c|c|c|c|c|c|c|}
\hline \multirow{2}{*}{ Constraints } & \multicolumn{4}{|c|}{ Extent } & \multirow{2}{*}{ CFI } & \multirow{2}{*}{ Rank order } \\
\hline & High & Medium & Low & Not at all & & \\
\hline Lack of capital to invest & 100 & 17 & 3 & 0 & 2.81 & 1 \\
\hline Lack of technical guidance & 92 & 28 & 0 & 0 & 2.77 & 2 \\
\hline Lack of improved Varity & 82 & 30 & 10 & 0 & 2.63 & 3 \\
\hline Lack of improved technology & 71 & 35 & 14 & 0 & 2.48 & 4 \\
\hline Introspection by forestry & 63 & 40 & 17 & 0 & 2.38 & 5 \\
\hline Lack of credit & 46 & 47 & 27 & 0 & 2.16 & 6 \\
\hline Disease and pest infestation & 42 & 50 & 28 & 0 & 2.12 & 7 \\
\hline Growing type & 55 & 35 & 21 & 9 & 2.13 & 8 \\
\hline Lack of land & 24 & 40 & 48 & 8 & 1.67 & 9 \\
\hline Seedling mortality rate & 4 & 72 & 40 & 4 & 1.63 & 10 \\
\hline Lack of seedling & 31 & 26 & 46 & 17 & 1.59 & 11 \\
\hline Lack of workers & 18 & 24 & 70 & 8 & 1.43 & 12 \\
\hline
\end{tabular}

Note: $\mathrm{CFI}=$ constraints facing index high $=3$, medium $=2$, low $=1$, and not at all $=0$. 
TABLE IV: SUMMARY OF MULTIPLE LINEAR REGRESSION WITH FOCUS VARIABLE EXPLAINED (N=120)

\begin{tabular}{|c|c|c|c|c|c|}
\hline \multirow{2}{*}{ Independent variable } & \multicolumn{2}{|c|}{ Unstandardized coefficients } & \multicolumn{2}{|c|}{ Standardized coefficients } & \multirow{2}{*}{ Sig. B } \\
\hline & $\mathrm{B}$ & Std. Error & Beta & $\mathrm{t}$ & \\
\hline Age & 0.020 & 0.021 & 0.073 & 0.950 & 0.344 \\
\hline Education & $0-.355$ & 0.021 & $-0.174 *$ & -2.180 & 0.031 \\
\hline Household size & 0.180 & 0.126 & 0.104 & 1.426 & 0.157 \\
\hline Homestead size & 4.284 & 10.567 & 0.092 & .405 & 0.686 \\
\hline Farm size & -3.171 & 1.523 & $-0.630 *$ & -2.082 & 0.040 \\
\hline Total number of agar tree per farmer & 0.000 & 0.000 & 0.197 & 0.831 & 0.408 \\
\hline Annual family income & -1.591 & 0.485 & $-0.339 * *$ & -3.278 & 0.001 \\
\hline Experience in agar cultivation & -0.011 & 0.053 & $-0.203 *$ & -2.209 & 0.045 \\
\hline Agar wood cultivation under trees & 0.043 & 0.040 & 0.111 & 1.060 & 0.291 \\
\hline Knowledge of Agar cultivation & 0.034 & 0.088 & 0.063 & 0.386 & 0.700 \\
\hline \multicolumn{6}{|c|}{ Adjusted R Square $=0.435 \mathrm{~F}$-value $=10.15$} \\
\hline
\end{tabular}

Note: $\mathrm{R}=0.69, \mathrm{R} 2=0.48$; If the $\mathrm{p}$-value is less than 0.05 , the level of significance is $95 \%$.

In predicting the variance of restrictions in agar tree cultivation, the coefficient of farm size was negative and significant. This indicated that the larger the farm holdings, the greater the farmers' experience in the study area, i.e., for everyone unit increase in farm size, the constraints faced drop by 3.171. Previously, we observed that the most significant barrier in the research sector was a shortage of cash (Table II). The larger farm necessitates a greater financial, labor, and resource commitment. As a result, huge agricultural holdings may experience difficulties cultivating agar trees.

A similar study conducted by [36] explained that the farm size which significantly associated with awareness and adoption of farming. Annual income of agar tree farmers was negative and significant. This indicated that the larger is the farm holding the more is the annual income of the farmers in the study area, i.e with one unit increase in annual income, the constraints faced by the farmers will decrease by 1.591. A similar result reported [31] that the farmers' previous experience with agar tree farming was poor and significant in predicting the restrictions. This meant that by increasing agar tree farming experience by one unit, the limitations in agar tree production were reduced by 0.011 . This might be due to fact that the increased knowledge of agar tree farming helps explore various options/alternatives to overcome the constraints, thus, lessens the extent or severity. Similar findings were reported by [33], [24].

\section{CONCLUSIONS}

Agar plantation was found very profitable as well as good for environmental benefits (carbon sequestration and biodiversity conservation) in the Barlekha upazila of Moulvibazar district due to its favorable climatic conditions. Among the major constraints faced by the agar tree farmers in the study area; lack of capital, unavailability of technical guidance and lack of improved variety were found significant. The degree of restriction is also controlled by the farmers' socioeconomic circumstances. Lack of capital and credit sources were anticipated to be critical determinants addressed by the farmers during the study. Furthermore, the farmers interviewed appeared to be in need of basic farming information and had limited access to extension services. However, adequate efforts by extension employees may be able to mitigate this problem. Several characteristics, including the farmers' education, farm size, annual revenue, and agar farming experience, were found to have a greater impact on the constraints. This highlighted an opportunity to improve those traits in order to reduce the degree of limitations that prevent agar tree farming from being profitable. Other considerations include number of trees, agarwood cultivation under trees and knowledge of agar farming were also found to be associated with the constraints.

Therefore, it will be wise to intervene by respective authority like Forest Department (FD) for providing improved interventions, such as training in agar farming and extension assistance to the farmers as regards to agar tree cultivation that would improve the profitability of agar production. In addition, various credit organizations (both GOs and NGOs) should provide readily available credit services to encourage agar cultivation in the study area and other areas with similar geographic and socio-economic conditions. For the agar-based economic sector in Bangladesh to flourish, it is also necessary to raise awareness of the environmental benefits of agar trees.

\section{ACKNOWLEDGMENT}

The first author acknowledges the National Science\& Technology (NST) fellowship by the Ministry of Science \& Technology (MoST), Government of the People's Republic of Bangladesh. The Authors also acknowledges Bangabandhu Sheikh Mujibur Rahman Agricultural University, Gazipur 1706, Bangladesh for technical support for this study.

\section{COMPETING INTERESTS}

Authors have declared that no competing interests exist.

\section{REFERENCES}

[1] R. A. Blanchette, "The genus Gyrinops is closely related to Aquilaria and in the past all species were considered to belong to Aquilaria, Cultivated Agarwood Training programs and Research in Papua New Guinea. Forest Pathology and Wood Microbiology Research Laboratory", Department of Plant Pathology, University of Minnesota, 2006.

[2] S Akter, M. T. Islam, M. Zulkefeli, \& S. I. Khan, "Agarwood production-a multidisciplinary field to be explored in Bangladesh", International Journal of Pharmaceutical and Life Sciences, 2(1), pp. 22-32, 2013

[3] Chakrabarty, A. Kumar, \& V. Menon, "Trade in agar wood", WWFIndia/TRAFFIC India, New Delhi, 1994.

[4] M. Chowdhury, R. Ali, M. D. Hussain, \& A. Ishida, "Present Status and Future Opportunity of Agar Cultivation in Bangladesh", DIWPA News Letter No.38. pp. 1-9, 2018. 
[5] S. Oldfield, C. Lusty, \& A. MacKinven, "The Word List of Threatened Trees" World Conservation Press, Cambridge, UK, 1998.

[6] A. Talukdar, "Evaluation of few biochemical parameters of the in vitro grown callus tissue of Aquilaria agallocha Roxb", Indian Journal of Life Sciences, 2(1), pp. 16-19, 2012.

[7] C. Y. Jim, "Cross-border itinerant poaching of agarwood in Hong Kong's peri-urban forests”, Urban Forestry \& Urban Greening, 14(2), pp. 420-431, 2015.

[8] M. S. A. Talucder, "'Opportunities and challenges of existing agroforestry practices in Sylhet region for food security" SAU Res. Prog. Rep. 05, 15, 2018a.

[9] M. S. A. Talucder, M. M. Haque, \& D. Saha, "Development of Agar (Aquilaria malaccensis) cultivation, propagation technique and its potentiality as agroforestry component in Bangladesh", A review, Journal of Sylhet Agriculture University, 3(2), pp. 149-157, 2016.

[10] M. Das, M. S. Uddin, M. A. Kashem, M. S. A. Talucder, T. B. Hye, \& T. Afroz, "Traditional Practices of Agarwood (Aquilaria Malaccensis) Plantation in Moulvibazar of Bangladesh", Int. J. Sustain. Crop Prod. 14(1), pp. 44-49, 2019.

[11] M. A. K. Hayder, L. M. Rahman, \& M. A. Rahman, "Experimental agar production project (in Bengali)", Department of Forests, Ministry of Environment and Forest, Dhaka, pp. 1-16 2005.

[12] M. Rahman, N. M. Nath, S. Sarker, M. Adnan, \& M. Islam, "Management and economic aspects of growing Aquilaria agallocha Roxb. In Bangladesh", Small-scale forestry, 14(4), pp. 459-478, 2015.

[13] M. W. Baksha, S. Akhter, A. C. Basak, \& M. S. Rahman, "Bangladeshy agar chas o agar kutirsilpo (Agar cultivation and cottage industry in Bangladesh)”, Bangladesh Forest Research Institute, Chittagong, pp. 20 (a booklet in Bangla), 2009.

[14] The Independent. Exploring Agarwood's export potential, (2016), (Accessed 31 July 2021) https://www.theindependentbd.com > arcprint $>$ details.

[15] M. S. A. Talucder, "Evaluation of tree-crop interaction from existing agroforestry systems in Sylhet region for food security by the lens of Climate-Smart Agriculture framework", Project Completion Report, National Agricultural Technology Program-Phase II Project (NATP2), (BARC), Dhaka-1215, Bangladesh, 2018b.

[16] M. Q., Chowdhury, A. Z. Rashid, \& M. M. Afrad, "The Status of agar (Aquilaria agallocha Roxb.) based small-scale cottage industries in Sylhet region of Bangladesh", Bangladesh J Resour Dev, 2(1), pp. 122. 2003 .

[17] M. S. Uddin, S. A. Mukul, M. A. Khan, S. A. Alamgir, M. Y. Harun, \& M. S. Alam, "Small-scale agar (Aquilaria agallocha Roxb.) based cottage enterprises in Maulvibazar district of Bangladesh: production, marketing and potential contribution to rural development", Smallscale Forestry, 7(2), pp. 139-149, 2008.

[18] S. Ali, \& M. A. Kashem, "An overview on Growth and Development of Agar Plant (Aquilaria malaccensis Roxb) Through Management Practices in Bangladesh", International Journal of Research in Agriculture and Forestry Volume 6, Issue 7, 2019, pp. 6-11, 2019.

[19] S. Hossen, \& M. K. Hossain, "Initial growth performance of agar (Aquilaria malaccensis) plantations at public and private sectors in Bangladesh” J. Biosci. Agric. Res, 10(02), pp. 871-876, 2016.

[20] BARC (Bangladesh Agricultural Research Council), "Soil fertility status of different agroecological zones" BARC Soils Publication, 45, pp. 15-32, 2005.

[21] J. R. Fraenkel, N. E. Wallen, \& H. H. Hyun, "How to Design and Evaluate Research in Education" 8th ed. McGraw-Hill, New York, 2012.

[22] M. A. Amin, M. A. Bashar, N. Akhter, M. Afroj, M. Z. Islam, M. M. Rahman, \& M. A. Baque, "Constraints faced by the farmers in IPM practices in rice cultivation", J. Sci. Tech. Environ. Info, 4, pp. 245$250,2016$.

[23] M. S. Rahman, R. K. Roy, \& S. "Huda, Constraints and perceived scope for practicing small scale aquaculture in Thakurgaon District, Bangladesh", Bangladesh Journal of Extension Education ISSN, 1011, pp. 3916, 2014.

[24] J. C. Pandit, \& N. C. Basak, "Constraints faced by the farmers in commercial cultivation of vegetables", Journal of the Bangladesh Agricultural University, 11(2), pp. 193-198, 2013.

[25] A. Nazif, N. I. Mohammed, A. Malakahmad, \& M. S. Abualqumboz, "Application of step wise regression analysis in predicting future particulate matter concentration episode", Water, Air, \& Soil Pollution, 227(4), pp. 117, 2016.

[26] BBS (Bangladesh Bureau of Statistics), Statistical Year Book of Bangladesh, Ministry of Planning, Government of the People's Republic of Bangladesh, 2017.

[27] S. M. Alam, "Production, Processing and Economic aspects of Agar Tree (Aquilaria Malaccensis) as an Agroforestry Species in
Moulvibazar District of Bangladesh", M. S. thesis, Department of Agroforestry \& Environment, BSMRAU, Gazipur, Bangladesh, 2006.

[28] O. J. Olaoye, S. S. Ashley-Dejo, E. O. Fakoya, N. B. Ikeweinwe, W. O. Alegbeleye, F. O. Ashaolu, \& O. A. Adelaja, "Assessment of socio-economic analysis of fish farming in Oyo State", Nigeria, Global Journal of Science Frontier Research Agriculture and Veterinary, 13(9), pp. 45-55, 2013.

[29] S. O. Ogunmefun, \& A. I. Achike, "Socioeconomic characteristics and constraints of pond fish farmers in Lagos State", Nigeria. Agricultural Science Research Journal, 7(10), pp. 304-317, 2017.

[30] P. Das, S. A. Sabur, M. S. Palash, \& M. Hasan, "An Economic Analysis of Agar-Wood Production in North-Eastern Bangladesh", Asian J. of Economics, Business and Accounting, pp. 1-8, 2018.

[31] S. S. Hasan, S. Roy, S. Saha, \& M. Z. Hoque, "Assessment of the Farmers' Perception on Vermicompost as Waste Management Practice and Economic Return in Some Areas of Bangladesh", European Journal of Agriculture and Food Sciences, 3(3), pp. 14-20, 2021.

[32] M. K. Ghosh, S. S. Hasan, M. E. Haque, \& M. J. Uddin, "Knowledge of farmers to sustainable agriculture practices: A case study in Southwestern region of Bangladesh" Scholars Journal of Agriculture and Veterinary Sciences, 2020.

[33] M. N. Uddin, K. H. Kabir, D. Roy, M. T. Hasan, M. A. Sarker, \& E. S. Dunn, "Understanding the constraints and its related factors in tilapia (Oreochromis sp.) fish culture at farm level: A case from Bangladesh", Aquaculture, 530, pp. 735927, 2021.

[34] C. Mulinya, "Factors affecting small scale farmers coping strategies to climate change in Kakamega County in Kenya", IOSR Journal of Humanities and Social Science (IOSR-JHSS), 22(2), pp. 100-109, 2017.

[35] A. B. M. S. Islam, M. G. Farouque, \& D. Roy, "Problem Confronted by the Fish Farmers in Practicing Semi-intensive Climbing Perch (Anabus testubineus) Farming”, Bangladesh Journal of Extension Education ISSN, 1011, pp. 3916, 2013.

[36] M. Muddassir, M. A. Noor, A. Ahmed, F. Aldosari, M. A. Waqas, M. A. Zia, \& M. W. Jalip, "Awareness and adoption level of fish farmers regarding recommended fish farming practices in Hafizabad", Pakistan. Journal of the Saudi Society of Agricultural Sciences, 18(1), pp. 41-48, 2019. 